This could be related to leaching of glutaraldehyde, as seen with the pulmonary anastomosis in the RV to pulmonary artery implantation in neonates. ${ }^{5}$ This gradient has responded satisfactorily to balloon dilation.

We have used a similar technique of implantation in 2 previous patients. The first, a neonate with Shone syndrome, received a 16-mm aortic homograft bicuspidized into a 10 $\mathrm{mm}$ valve. The valve failed secondarily as a result of severe thickening of the homograft wall. The second, a 2-year-old with intermediate atrioventricular septal defect with a mechanical valve replacement, developed intolerance to the anticoagulation regimen and as a result had a severe hemorrhagic stroke. The mechanical valve was replaced with a pulmonary autograft implanted with the technique described here. The valve is functioning well and is growing at more than 3 years of follow-up.

In the last 8 months, 3 other patients have received 12-mm Contegra conduits. All have Shone syndrome. One had his valve explanted after 3 weeks and replaced with a mechanical valve because the pulmonary hypertension did not recess. This patient eventually died of stroke. Two patients are alive with well-functioning Contegra valves and the absence of residual $\mathrm{LV}$ outflow tract obstruction but with failure to thrive and persistent pulmonary hypertension, suggesting that there may be more than valvular issues behind some severe Shone syndromes.

This original technique responds to a long-standing technical conundrum faced by our specialty. It should allow for somatic growth until an annular size adequate to accommodate the insertion of a mechanical valve can be achieved.

\section{References}

1. Oppido G, Davies B, McMullan DM, Cochrane AD, Cheung MM, d'Udekem Y, et al. Surgical treatment of congenital mitral valve disease: midterm results of a repair-oriented policy. J Thorac Cardiovasc Surg. 2008;135:1313-20; discussion 1320-1.

2. Caldarone CA, Raghuveer G, Hills CB, Atkins DL, Burns TL, Behrendt DM, et al. Long-term survival after mitral valve replacement in children aged $<5$ years: a multi-institutional study. Circulation. 2001;104(12 Suppl 1):I143-7.

3. Athanasiou T, Cherian A, Ross D. The Ross II procedure: pulmonary autograft in the mitral position. Ann Thorac Surg. 2004;78:1489-95.

4. Abdullah I, Ramirez FB, McElhinney DB, Lock JE, del Nido PJ, Emani S. Modification of a stented bovine jugular vein conduit (Melody valve) for surgical mitral valve replacement. Ann Thorac Surg. 2012;94:e97-8.

5. Fiore AC, Ruzmetov M, Huynh D, Hanley S, Rodefeld MD, Turrentine MW, et al. Comparison of bovine jugular vein with pulmonary homograft conduits in children less than 2 years of age. Eur J Cardiothorac Surg. 2010;38: 318-25.

\title{
Bilobectomy with superior pulmonary vein reconstruction with a greater saphenous vein autograft to avoid pneumonectomy
}

\author{
Kazuhiro Wakida, MD, ${ }^{\mathrm{a}}$ Goichi Yotsumoto, $\mathrm{MD}, \mathrm{PhD},{ }^{\mathrm{b}}$ Naoya Yokomakura, $\mathrm{MD}, \mathrm{PhD},{ }^{\mathrm{a}}$ and \\ Masami Sato, MD, PhD, ${ }^{\text {a }}$ Sakuragaoka, Japan
}

In cases of advanced lung cancer with involvement of hilar lymph nodes, wide resection is often required because of vascular and bronchial involvement. Pulmonary artery angioplasty is often performed with lung lobectomy, whereas pulmonary vein angioplasty is rare. The use of

\footnotetext{
From the Department of General Thoracic Surgery ${ }^{\mathrm{a}}$ and Cardiovascular and Gastroenterological Surgery, ${ }^{\mathrm{b}}$ Advanced Therapeutics Cardiovascular and Respiratory Disorders, Graduate School of Medical and Dental Sciences, Kagoshima University, Sakuragaoka, Japan.

Disclosures: Authors have nothing to disclose with regard to commercial support

Received for publication April 21, 2014; revisions received Aug 31, 2014; accepted for publication Oct 6, 2014; available ahead of print Nov 7, 2014.

Address for reprints: Masami Sato, MD, PhD, Department of General Thoracic Surgery, Graduate School of Medical and Dental Sciences, Kagoshima University, 8-35-1, Sakuragaoka, Kagoshima 890-8520, Japan (E-mail: m-sato@m2.kufm. kagoshima-u.ac.jp).

J Thorac Cardiovasc Surg 2015;149:392-4

$0022-5223 / \$ 36.00$

Copyright (C) 2015 by The American Association for Thoracic Surgery

http://dx.doi.org/10.1016/j.jtcvs.2014.10.039
}

venous angioplasty, however, could decrease the volume of lung to be resected and thereby preserve lung function. We performed middle and lower lobectomy for a right middle lobe cancer with the greater saphenous vein for superior pulmonary vein angioplasty to avoid a pneumonectomy.

\section{CLINICAL SUMMARY}

An 84-year-old man had a 50-mm right-sided tumor at the S5 level with an enlarged interlobar lymph node seen on chest computed tomography. He was referred to our hospital with a diagnosis of cT2bN1M0 stage IIB non-small cell carcinoma and diabetes. The computed tomography suggested middle lobe abscess and empyema (Figure 1). We therefore performed an emergency operation.

Right middle and lower lobectomy was considered necessary for complete resection because the interlobar lymph node deeply infiltrated the basal artery. Furthermore, the tumor infiltrated into the root of the middle lobe veins $(\mathrm{V} 4+5)$. 


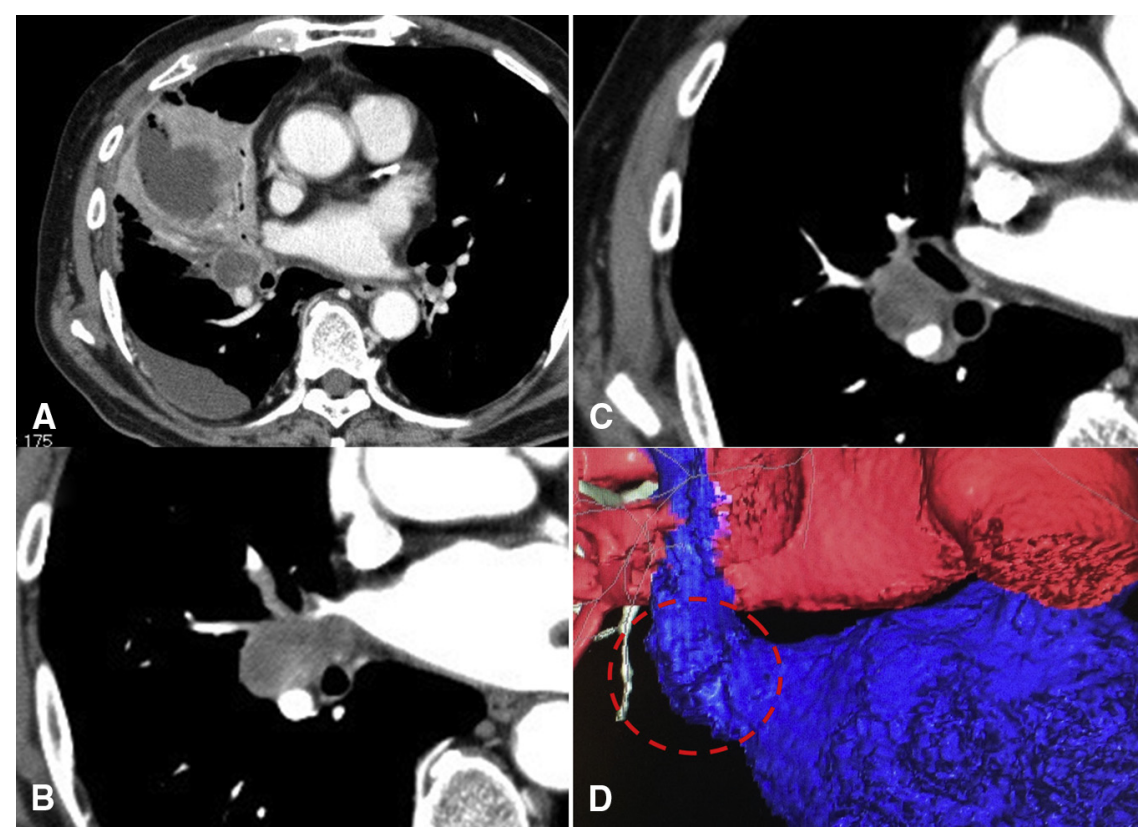

FIGURE 1. Chest computed tomographic images. A, Two weeks after bronchoscopy. B, Lymph node around the middle lobe bronchus invading the superior pulmonary vein. C, Interlobar lymph node invading the basal pulmonary artery. D, Three-dimensional image of the pulmonary artery and vein after operation.

Because the patient's postoperative forced expiratory volume in 1 second was $46 \%$ of the expected rate, we decided to preserve the right upper lobe to avoid postoperative respiratory failure. For these reasons, we needed to perform venous angioplasty. We were unable to use either artificial material or autograft such as pericardium or the azygos vein, however, because of the empyema. We anticipated that the postresection defect in the vein would be large and that direct suture of the defect would cause stenosis or obstruction to the upper lobe vein. We therefore decided to use the greater saphenous vein as a patch.

During the operation, we entered the thoracic cavity after harvesting the greater saphenous vein (Figure 2, B). The tumor and enlarged interlobar lymph node infiltrated into the basal artery and the root of the middle lobe veins. Lower and middle lobectomies were therefore necessary. For

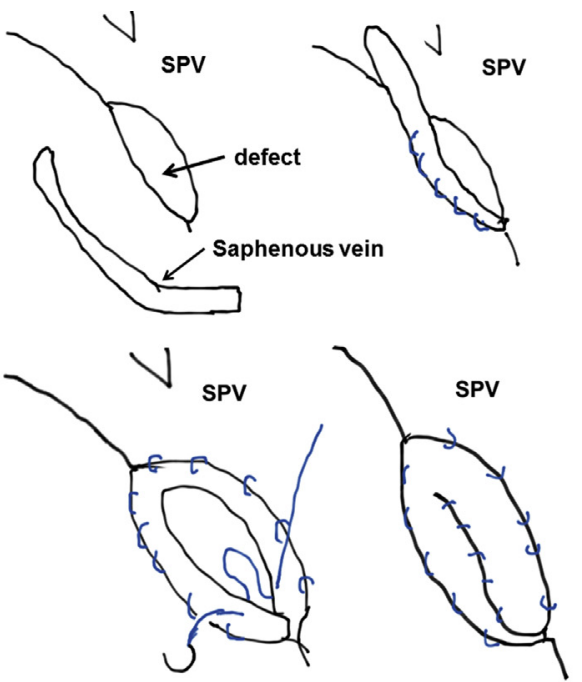

A

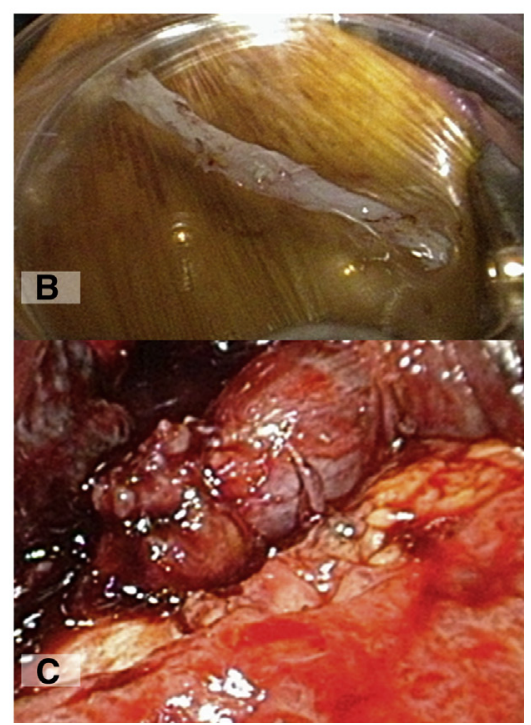

FIGURE 2. A, Illustrations of the procedures to reconstruct the superior pulmonary vein (SPV). B, Greater saphenous vein for autologous patch. C, Final view of reconstructed superior pulmonary vein. 
complete resection, the root of $\mathrm{V} 4+5$ had to be removed. We performed a pericardial incision, clamped the superior pulmonary vein, and cut off $\mathrm{V} 4+5$ (Figure 2, A upper left). The size of the hole was $20 \times 15 \mathrm{~mm}$, which was larger than expected, so the vein was used to patch a defect in the superior pulmonary vein (Figure 2, A upper right, lower right, and lower left, and $C$ ). Moreover, because we anticipated that the pulmonary vein would be stenosed by downward deviation of the upper lobe after resection, we made a wide incision in the pericardium around the superior pulmonary vein approximately three-quarters around. No anticoagulant therapy was given.

According to the chest computed tomography performed 2 weeks after surgery, there were no superior pulmonary vein stenoses or blood clots (Figure 1,D). The patient was discharged 3 weeks after surgery. Because of his age, postoperative adjuvant therapy was not carried out. There were no major problems noted at his outpatient visit 2 months after surgery.

\section{DISCUSSION}

Because of low pulmonary vein pressure relative to systemic circulation, it is necessary to prevent thrombosis when performing pulmonary vein angioplasty. We therefore carried out 2 procedures. One procedure was a wide patch with the greater saphenous vein for pulmonary vein plasty and the other was a three-quarters pericardial incision of the circumference of the superior pulmonary vein. The latter could prevent the superior pulmonary vein from bending at the lower deviation of the upper lobe after middle and lower lobectomies. The former made it possible to reconstruct widely without reducing the area of the crosssection at the angioplasty. We used the non-infected greater vein rather than infected pericardium or artificial patches. First, we sewed the autograft into pulmonary vein hole with a ring shape (Figure 2, A upper left, upper right, and lower left). We then closed the central hole. These made a wide patch.

Berthet and colleagues ${ }^{1}$ reported 10 cases with cryopreserved allograft for pulmonary artery replacement in sleeve resection. There have also been reports of autografts of pericardium and azygos vein being used in lobectomy. ${ }^{2,3}$ These cases, however, concerned angioplasty for reconstruction of the pulmonary artery. Only Narita and associates ${ }^{4}$ reported reconstruction of the pulmonary vein. Pulmonary congestion caused by venous stenosis or thrombosis could be lethal. According to a personal communication, there were 2 deaths of pulmonary congestion after the pulmonary vein angioplasty by a simple patch or direct suture. Our method introduced here could be an alternative procedure to avoid pulmonary congestion. Further verification of these cases is necessary.

\section{CONCLUSIONS}

A wide patch superior pulmonary vein reconstruction with a three-quarter pericardial incision around the superior pulmonary vein appears to be a valid approach to avoid pneumonectomy.

\section{References}

1. Berthet JP, Boada M, Paradela M, Molins L, Matecki S, Marty-Ané CH, et al. Pulmonary sleeve resection in locally advanced lung cancer using cryopreserved allograft for pulmonary artery replacement. J Thorac Cardiovasc Surg. 2013;146: 1191-7.

2. Cerezo F, Cano JR, Espinosa D, Salvatierra A. New technique for pulmonary artery reconstruction. Eur J Cardiothorac Surg. 2009;36:422-3.

3. Xuegang L, Chao S, Zhen T, Xiaojun L, Ge L, Lei Z. Pulmonary artery reconstruction using autologous pericardium or azygos venae substitute for surgical treatment of central non-small cell lung cancer. Cell Biochem Biophys. 2013;67: 949-55.

4. Narita K, Iwanami H, Hiyoshi H, Tachibana M, Hasegawa K, Sakonji M, et al. [Pulmonary vein reconstruction for lung carcinoma]. Kyobu Geka. 1999;52: 30-4. 